\title{
Effects of social mobility from childhood to adolescence on BMI
}

\author{
Ana Paula Muraro ${ }^{1, *}$, Regina Maria Veras Gonçalves-Silva ${ }^{2}$, Márcia Gonçalves Ferreira ${ }^{2}$ \\ and Rosely Sichieri ${ }^{3}$ \\ ${ }^{1}$ Instituto de Saúde Coletiva, Universidade Federal de Mato Grosso, Av. Fernando Corrêa da Costa 2367, Bairro \\ Boa Esperança, Bloco CCBS III, CEP 78060-900, Cuiabá, MT, Brasil: '2Departamento de Alimentação e Nutrição, \\ Universidade Federal do Mato Grosso, Cuiabá, MT, Brasil: ${ }^{3}$ Departamento de Epidemiologia, Instituto de Medicina \\ Social, Universidade do Estado do Rio de Janeiro, Rio de Janeiro, RJ, Brasil
}

Submitted 1 June 2014: Final revision received 22 March 2015: Accepted 21 April 2015: First published online 11 June 2015

\begin{abstract}
Objective: Little is known about the contribution of childhood socio-economic position (SEP) and social mobility to weight change. The present study evaluated the effect of family SEP during the pre-school years and social mobility on BMI between birth and adolescence.

Design: Longitudinal. The SEP of each child's family was classified according to an asset-based wealth index as low, medium or high. Four different categories of childhood-adolescence SEP groups were created in order to examine social mobility: low-medium/high, medium-medium, medium-high and high-high/ medium. For each of these categories, BMI was tracked from birth to adolescence. Linear mixed-effects models were used to analyse the data.

Setting: Cuiabá-MT, Brazil.

Subjects: A population-based cohort of children born between 1994 and 1999 was assessed between 1999 and 2000, and again between 2009 and 2011.

Results: A total of 1716 adolescents were followed from childhood to adolescence ( $71.4 \%$ of baseline). The prevalence of overweight/obesity was $20.4 \%$ in childhood and $27.7 \%$ in adolescence. A higher SEP in childhood was associated with a greater prevalence of overweight in adolescence. Expressive upward social mobility occurred, mainly in the lowest SEP group. There was a greater rate of change in BMI between birth and adolescence among children with a higher SEP in childhood and children who remained in the higher SEP from childhood to adolescence. Conclusion: Individuals from a higher SEP in childhood and those who remained in the higher social classes showed greater rate of change in BMI. Thus, initial SEP was the major determinant of changes in BMI.
\end{abstract}

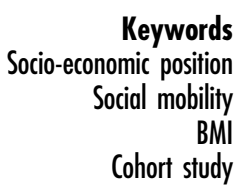

The prevalence of overweight in childhood and adolescence has increased in low- and middle-income countries, this increase largely being driven by economic growth and rapid urbanization ${ }^{(1)}$. In Brazil, the prevalence of obesity has increased among children and adolescents mainly in the last decade. From 1975 to 1989, the prevalence of overweight was similar for all income groups, but from 1989 to 2003 there was a greater increase in this prevalence among lower than among higher economic groups ${ }^{(2,3)}$, although a positive association between socio-economic position (SEP) and prevalence of overweight remained.

Thus SEP is clearly related to obesity, but the effect of social mobility on excess adiposity is not well understood. Some studies conducted in high-income countries have shown that social mobility can mitigate the negative effects of socioeconomic disadvantage in early life ${ }^{(4,5)}$ on adiposity in adolescence $^{(6)}$, but others have not been able to show this ${ }^{(7,8)}$. Controversy in studies conducted in these countries may be due to small differences in the risk factors for obesity among the socio-economic levels and small social mobility. In contrast, Brazil has shown in the last decade a huge social mobility of the low-income population, with an increase of the per capita income of Brazilians, particularly among the poorest ${ }^{(9)}$.

The relationship between social mobility and adiposity has been evaluated in two Brazilian birth cohorts and the results are also conflicting. In one cohort, upward mobility was associated with increased protection against high adiposity in adult women, but not in men ${ }^{(10)}$. In the other cohort $^{(11)}$, overweight was approximately twice as common among men who were never poor, but among women the opposite was observed: the prevalence of overweight was highest among women who were poor 
since childhood. Both cohorts studied in Brazil did not cover the period with the greatest social mobility, which has occurred in the last decade. Thus, our cohort data following children from birth, evaluated in 1999-2000 and 2009-2011, may be more adequate to explore the influence of socially patterned childhood exposures on later life outcomes, which can be due to biological programming during critical periods of growth and through the early acquisition of unhealthy lifestyles. Mobility due to a greater purchasing power of households has been associated with greater food availability among poor families $^{(12)}$, but not necessarily to a healthy diet. Thus, our hypothesis is that a positive social mobility in Brazil would be positively associated with BMI trajectory.

Studying changes in adiposity over time and across SEP groups is important in order to anticipate emerging patterns of disease. Therefore, the present study evaluated the effect of social mobility on BMI trajectory from childhood to adolescence in a cohort of Brazilian children.

\section{Methods}

\section{Subjects}

A cohort of children born between 1994 and 1999 in Cuiabá, Brazil ( $n$ 2405) was randomly selected from primary-care centres between May 1999 and January 2000 (i.e. the subjects ranged in age from 0 to 5 years). In 2000 , the population of Cuiabá was $483346 ; 98.6 \%$ of the residents lived in the urban area and $8.4 \%$ ( $n$ 43 197) were younger than 5 years ${ }^{(13)}$. The full description of the sampling plan of this cohort has been given elsewhere ${ }^{(14)}$. Briefly, from the thirty-eight primary-care centres in Cuiabá, ten were randomly selected and the parents or guardians of approximately 240 children at each clinic were interviewed ( $n$ 2405). The refusal rate was $0 \cdot 4 \%$.

All subjects enrolled at baseline were eligible for followup study at their schools between 2009 and 2011. In Brazil, approximately $95 \%$ of children aged $10-14$ years and $78 \%$ of children aged 15-17 years attend school ${ }^{(15)}$. The annual school census in Brazil was used to identify the cohort. The national census includes all public and private schools throughout the country and by the child's name, date of birth and mother's name, $86.8 \%$ ( $n$ 2088) of the subjects (now adolescents) and their schools were identified. In addition, five deaths were identified in the Mortality Information System $^{(16)}$. Further details are provided in the paper by Gonçalves-Silva et al. ${ }^{(17)}$

In the follow-up after 11 years, $14.4 \%$ of the baseline children had moved to other cities. We attempted to interview all children living in Cuiabá or in cities near Cuiabá, or those who moved to cities where more than ten children of the cohort were living. Therefore, fieldwork was carried out between 2009 and 2011 in public and private schools in Cuiabá as well as additional cities. One city, Várzea Grande, is geographically and economically integrated with Cuiabá. The others were seventeen cities located within the state of Mato Grosso (near the capital) and five capital cities from other Brazilian states (Campo Grande-MS, Brasília-DF, São Paulo-SP, Rio de Janeiro-RJ and Goiânia-GO). Information about birth (e.g. length and weight) was obtained from hospital records, but all outcomes and major variables at pre-school age and adolescence were measured by the researchers.

The study was approved by the Ethics Committee of the Júlio Müller University Hospital, Federal University of Mato Grosso (651/CEP-HUJM/2009 Protocol). Parents or guardians of the participating adolescents gave written consent.

\section{Measures}

At the first evaluation, when the children were of preschool age (1999-2000), information about demographic and socio-economic characteristics was obtained via an interview with the parents or guardians. In 2009-2011, the subjects (then adolescents) were interviewed about socio-economic and lifestyle factors using a pre-tested questionnaire. At both interviews, anthropometric measurements were collected by trained fieldworkers according to the techniques recommended by Lohman et al. ${ }^{(18)}$.

From the anthropometric measures obtained at the first interview and at follow-up, values of BMI $\left(\mathrm{kg} / \mathrm{m}^{2}\right)$ for age and sex were calculated and expressed in $Z$-scores according to the growth curves published by the WHO (Multicentre Growth Reference study of 2006 for $<5$ years and growth reference data of 2007 for 5-19 years ${ }^{(19,20)}$. Scores were calculated using the WHO Anthro program for children aged $0-5$ years and the WHO AnthroPlus program for those aged 5-19 years, and cut-offs for overweight and obesity were those recommended by the $\mathrm{WHO}^{(21)}$.

The socio-economic level of the families was based on the number of home appliances, cars and paid maids, and the educational level of the head of the household, according the 'Brazil criterion' of economic classification $^{(22,23)}$. This system has five classes: A (higher), B, C, D and $\mathrm{E}$ (lower). For analysis, individuals were reclassified into three SEP groups: low (class E), medium (classes C and D) and high (classes A and B). To examine social mobility, individuals were classified into six categories based on changes in SEP occurring between pre-school and adolescence: (i) low-medium, those who were classified in the low class at the first evaluation and in the medium class at the second evaluation; (ii) low-high, those who were classified in the low class at the first evaluation and in the high class at the second evaluation; (iii) medium-medium, those who were in the medium class at both evaluations; (iv) medium-high, those who were in the medium class at the first evaluation and the high class at the second; (v) high-high, those who were in the high class at both evaluations; and (vi) high-medium, those who were in the high class at the first evaluation and in the medium class at the second. Because the categories low-high and high-medium 
each contained a small number of individuals ( $n 15$ and $n 29$, respectively), those two groups were reclassified into low-medium/high and high-high/medium.

\section{Data analysis}

The mean $Z$-scores for BMI-for-age in pre-school age and adolescence were compared using the Student's $t$ test and ANOVA. For the longitudinal analysis, BMI was the outcome because it is considered a better measure of change in adiposity in growing children and adolescents than BMI $Z$-score ${ }^{(24,25)}$. Linear mixed-effects models (SAS PROC MIXED) were used to assess the effects of early childhood SEP and social mobility on BMI from birth to adolescence accounting for the correlation between measurements ${ }^{(26)}$. Main effects of time, social mobility and an interaction between social mobility and time were tested. A significant interaction provides evidence for a differential rate of growth in BMI over time. Regression residuals were examined graphically to assess goodness of the fit. Analyses were performed with the statistical software package SAS version 9.3.

\section{Results}

At first evaluation, 2405 pre-school children had their height and weight measured. Length and weight at birth were obtained from hospital records on 2394 (99.5\%). After approximately 11 years, 1716 adolescents were measured and interviewed $(71.4 \%$ of baseline). The mean age at the first evaluation was 1.5 (SD 1.4) years and at adolescence was 12.1 (SD 1.4 ) years. The prevalence of overweight and obesity was $15.7 \%(n 270)$ and $4.7 \%$ ( $n$ 80), respectively, for children and 18.4\% ( $n$ 315) and 9.3\% ( $n$ 160), respectively, for adolescents. The prevalence of overweight/obesity increased by $37.7 \%$ in this period, with a greater increase among girls than boys ( $44 \% v .28 \%$ ).

The mean BMI-for-age was higher among adolescents from the high SEP group and among those whose mothers had a higher education level (Table 1). The association between SEP at pre-school age and prevalence of overweight and obesity was more pronounced in adolescence than in childhood. At both evaluation periods, obesity was

Table 1 Mean BMI-for-age Z-score (and 95\% confidence interval) at childhood (0-5 years old) and adolescence (10-17 years old), according to selected characteristics of adolescents. Population-based cohort of children born between 1994 and 1999 , first evaluated between 1999 and 2000, and followed up between 2009 and 2011, Cuiabá, Brazil

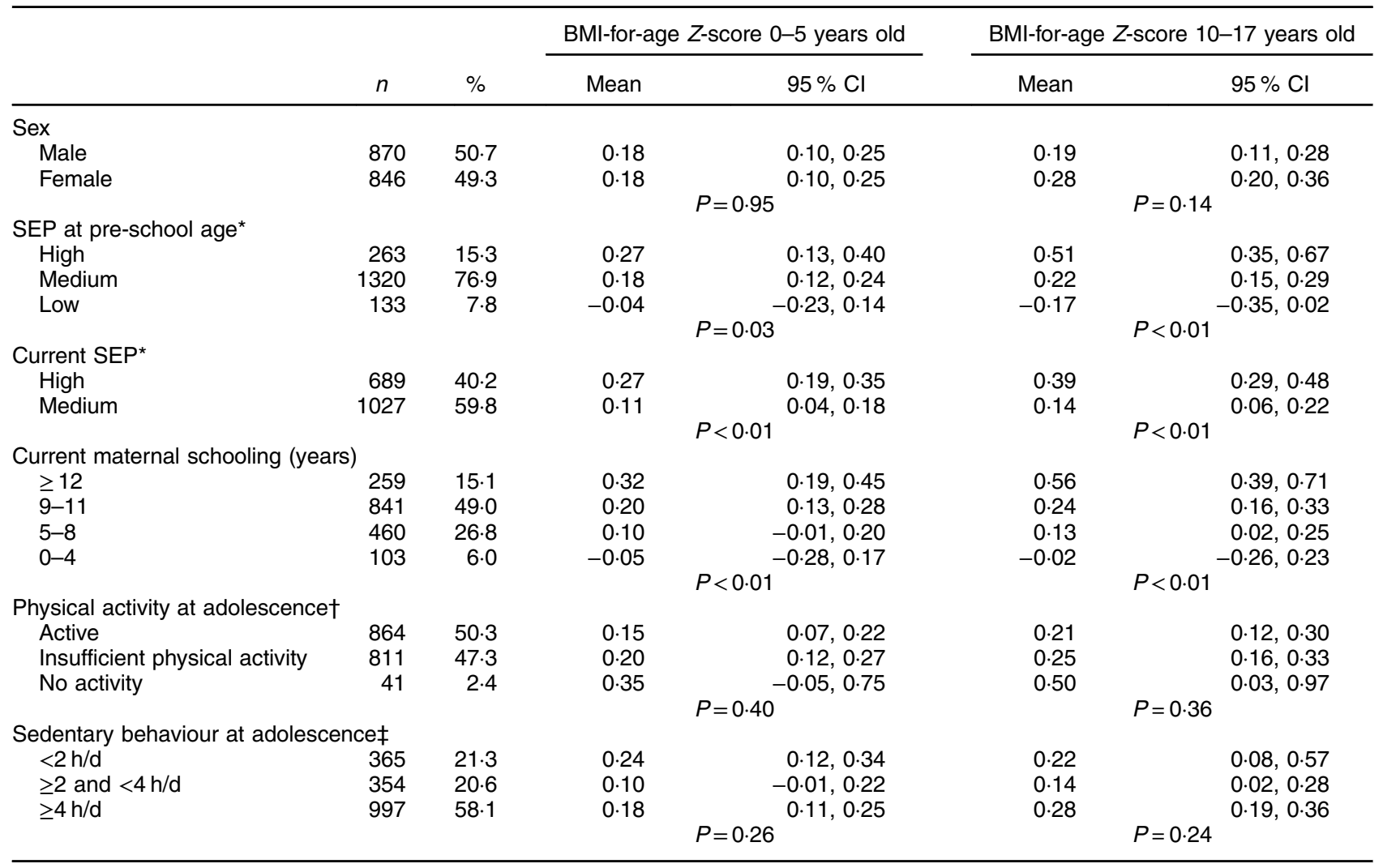

SEP, socio-economic position.

$P$ value from $t$ test or ANOVA.

Missing values: current SEP, $n$ 2; current maternal schooling, $n$ 53; current paternal schooling, $n 207$.

${ }^{*}$ According to the criteria of the Brazilian Marketing Research Association (childhood, 2003; adolescence, 2008) based on the number of home appliances, cars and paid maids, and education level of the head of household: high = classes $A$ and $B$; medium $=$ classes $C$ and $D$; low $=$ class $E$.

†Minutes per day: active = more than $300 \mathrm{~min} /$ week; insufficient physical activity =less than $300 \mathrm{~min} /$ week; and inactive $=0 \mathrm{~min} / \mathrm{week}$.

łHours per day watching television, playing passive video games or playing on the computer. 
(a)

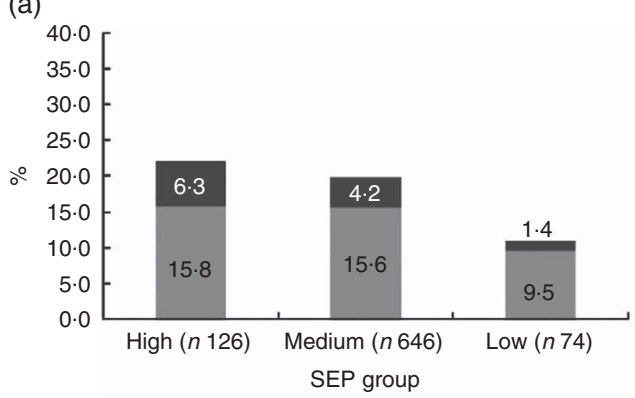

(c)

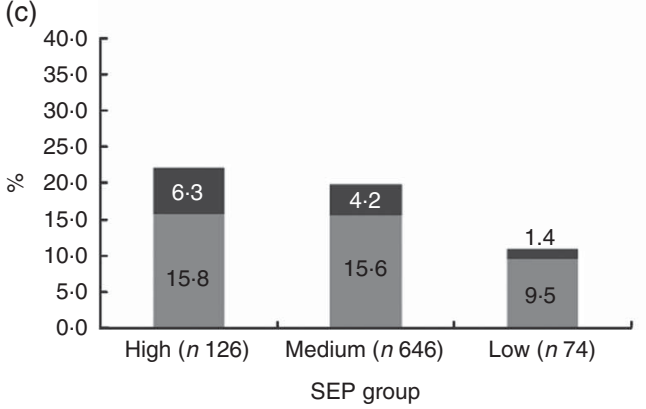

(b)

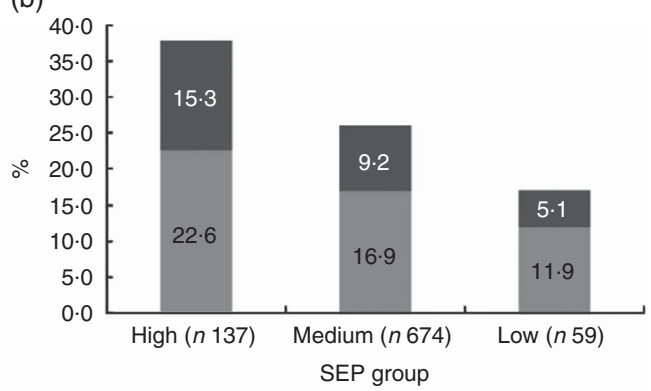

(d)

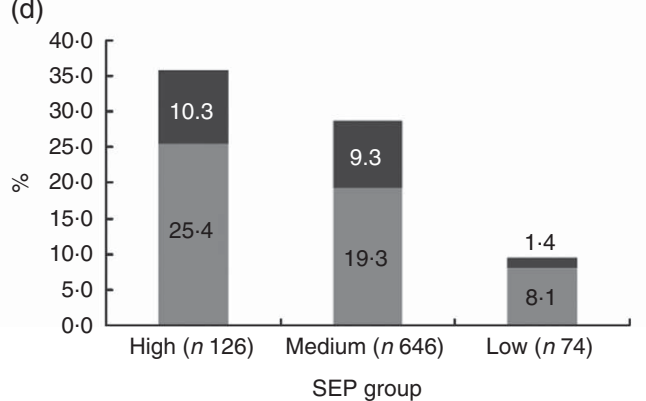

Fig. 1 Prevalence of overweight $(\square)$ and obesity $(\square)$ in childhood (0-5 years old) and adolescence (10-17 years old), according to socio-economic position (SEP) at pre-school age and sex: (a) males in childhood $(P=0.79$ ); (b) males in adolescence $(P=0.01$ ); (c) females in childhood $(P=0.25)$; (d) females in adolescence $(P<0.01)$. $P$ values refer to the difference between classifications of BMI according to SEP. Population-based cohort of children born between 1994 and 1999, first evaluated between 1999 and 2000 , and followed up between 2009 and 2011, Cuiabá, Brazil

more prevalent among subjects in the highest SEP group than among those in the lowest (see Fig. 1).

In terms of social mobility, $15 \cdot 3 \%$ ( $n$ 263) of subjects were classified as high-high/medium, $51.3 \%(n$ 880) as medium-medium, $25.6 \%(n$ 440) as medium-high and $7 \cdot 8 \%$ ( $n$ 133) as low-medium/high. At follow-up, there was only one adolescent in class E. Details of social mobility are provided in the online supplementary material, Supplemental Fig. 1. Social mobility had little impact on the prevalence of overweight and obesity, and those who remained in the higher SEP classes had the highest prevalence (Fig. 2).

The data were analysed using BMI as a continuous variable (Figs 3 and 4). Figure 3(a) shows that, for males, mean BMI evaluated from birth to adolescence had a greater rate of change for subjects in the high SEP group as compared with those in other SEP groups. For girls, the change in BMI from birth to adolescence was lowest for participants in the low SEP group (Fig. 3(b)). Similarly, the results in Fig. 4 indicate that initial SEP was the major determinant of BMI changes. The regression coefficients adjusted for birth weight, their standard errors and $P$ values from Figs 3 and 4 are provided in Table 2 .

\section{Discussion}

We observed a greater increase in BMI between birth and adolescence among subjects who were in the high SEP group at pre-school age and among those who remained in the high SEP until adolescence. Thus, childhood social mobility did not influence changes in adiposity. Further, there was only a slight difference between sexes. This result is similar to that of another cohort of Brazilian children in which a greater change in BMI was observed among adolescents, both sexes, who were in the higher SEP group during early childhood ${ }^{(27)}$.

Despite the slight difference between sexes, the trend follows the same direction, with greater increases in BMI in the higher income classes. Two studies conducted in Brazil have shown a differential SEP-adiposity association by sex when evaluated in early adulthood: a positive association between the variables has been observed in men, whereas a negative association has been observed in women $^{(10,11)}$. Both studies were conducted in the most developed regions of the country, the South and Southeast, whereas our cohort is from the Midwest, a less developed region. Further investigation would be necessary to understand the underlying factors for regional variations.

The prevalence of overweight and obesity was greater among adolescents from the highest SEP compared with those from the lowest. In addition, there was a greater increase in the prevalence of overweight between childhood and adolescence among subjects in the higher SEP at pre-school age. Similar results were found by Matijasevich et $a l .{ }^{(28)}$, who studied the trends in socio-economic inequalities and their effect on overweight prevalence 
(a)

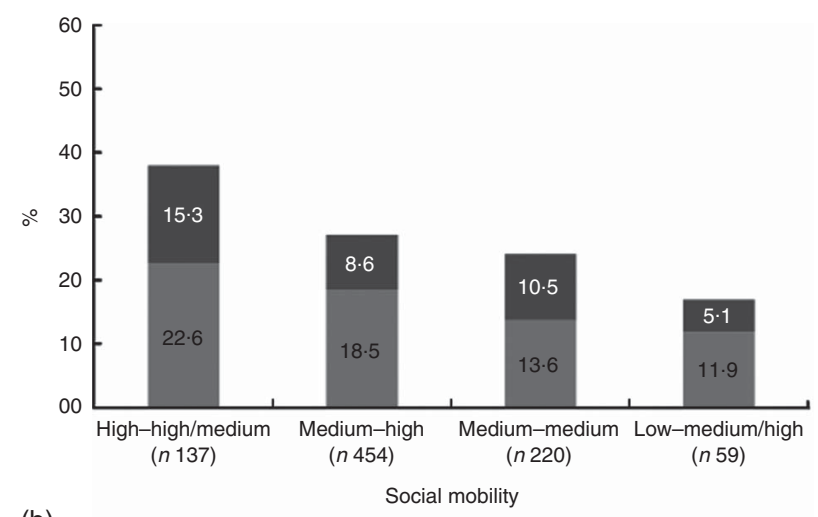

(b)

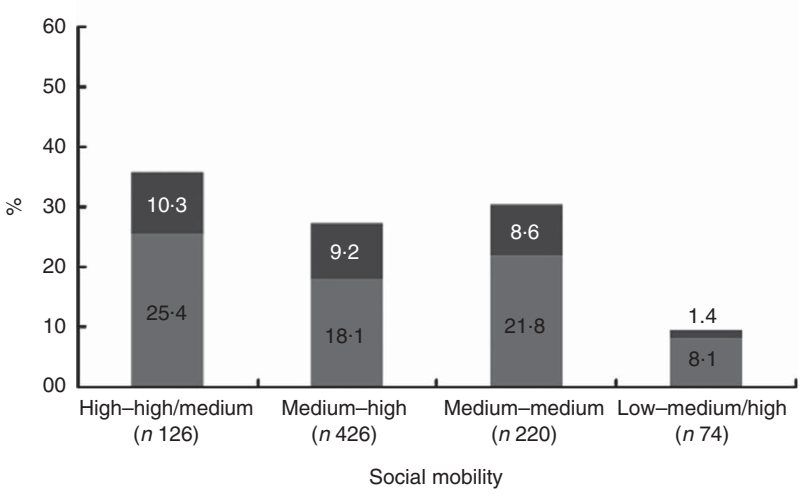

Fig. 2 Prevalence of overweight ( $\square$ ) and obesity ( $\square$ ) in childhood (0-5 years old) and at adolescence (10-17 years old), according to social mobility between childhood and adolescence and sex: (a) males $(P=0.02)$; (b) females $(P=0.01)$. $P$ values refer to the difference between classifications of BMI according to social mobility. Populationbased cohort of children born between 1994 and 1999, first evaluated between 1999 and 2000, and followed up between 2009 and 2011, Cuiabá, Brazil

among children in three population-based birth cohort studies (in 19821993 and 2004) in the city of Pelotas, Brazil. The authors observed a higher prevalence of overweight among those from families in the highest SEP, measured before birth, at nearly every follow-up over a 4-year period.

The highest degree of upward mobility among those in the lower economic classes in the present study is similar to that observed in other studies using criteria other than the 'Brazil criterion' used here. For example, in the Pelotas birth cohort, subjects were observed up to the age of 19 years and were classified by family income level ${ }^{(11)}$. Further, national data show the same trend and that in 2011 Brazil reached the lowest level of economic inequality in its history ${ }^{(9)}$, mainly due to the government-sponsored Bolsa Família cash transfer programme. The programme has had a positive impact on the food and nutrition security of participating families, but also resulted in an increase in the consumption of foods with a higher energy content and less nutritional value ${ }^{(12)}$. In addition, children from families
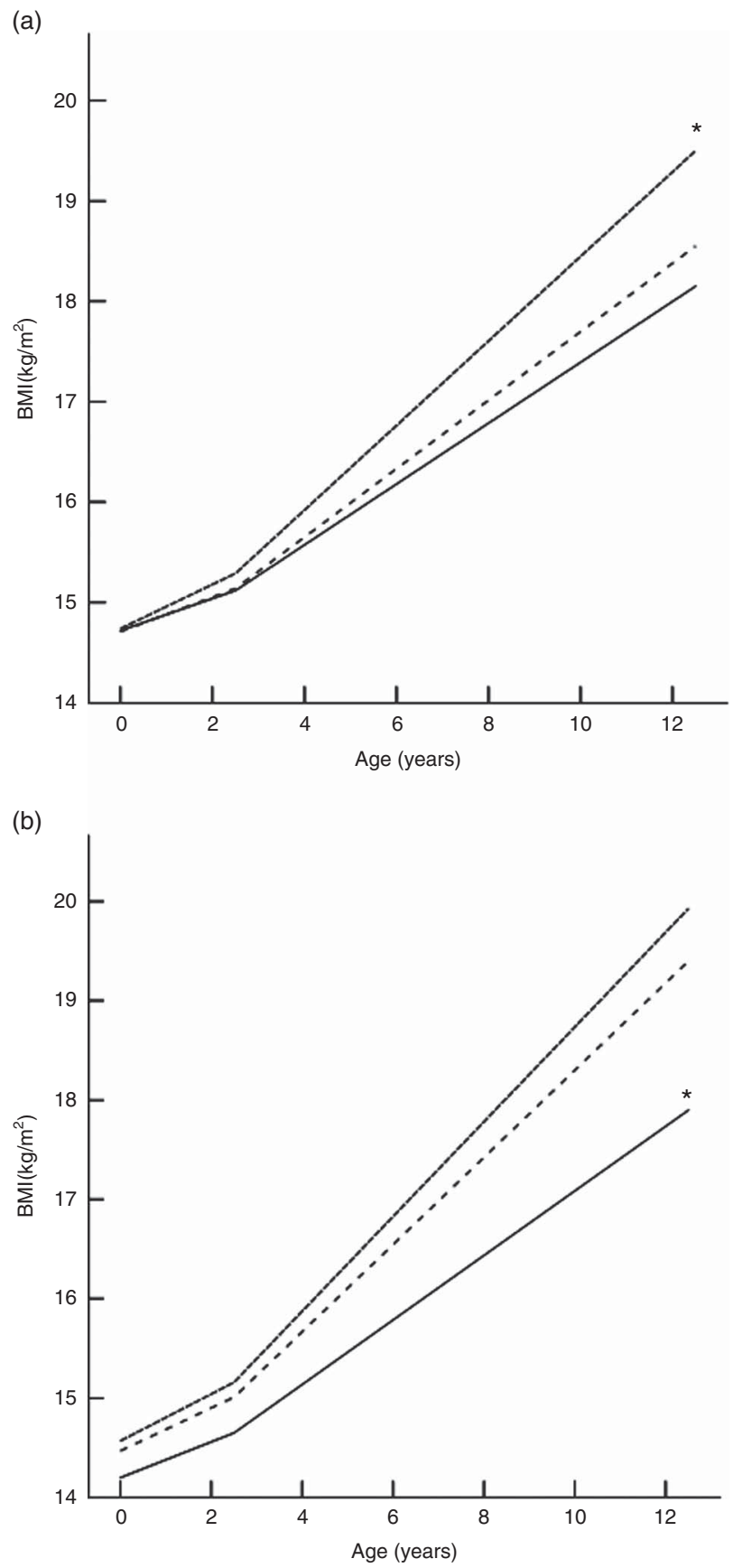

Fig. 3 Mean BMI (adjusted for birth weight) by age, according socio-economic position (SEP) at pre-school age (- - - -, high (males $n 137$, females $n 126$ ); - - - , medium (males $n 674$, females $n$ 646); - L low (males $n 59$, females $n 74)$ ) and sex: (a) males; (b) females. ${ }^{\star} P<0.05$ for the difference between classifications of BMI according to SEP. Populationbased cohort of children born between 1994 and 1999, first evaluated between 1999 and 2000, and followed up between 2009 and 2011, Cuiabá, Brazil

in the Bolsa Família programme were $26 \%$ more likely to have a normal height-for-age than those from families that were not in the programme, although there was no statistically significant difference for weight-for-height ${ }^{(29)}$. 
(a)

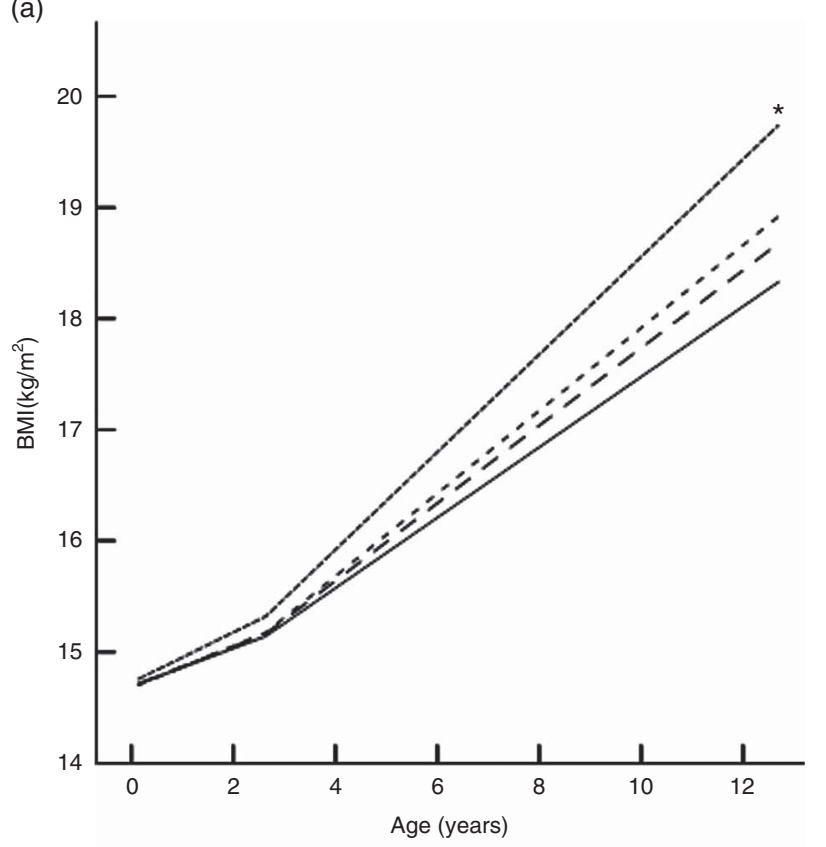

(b)

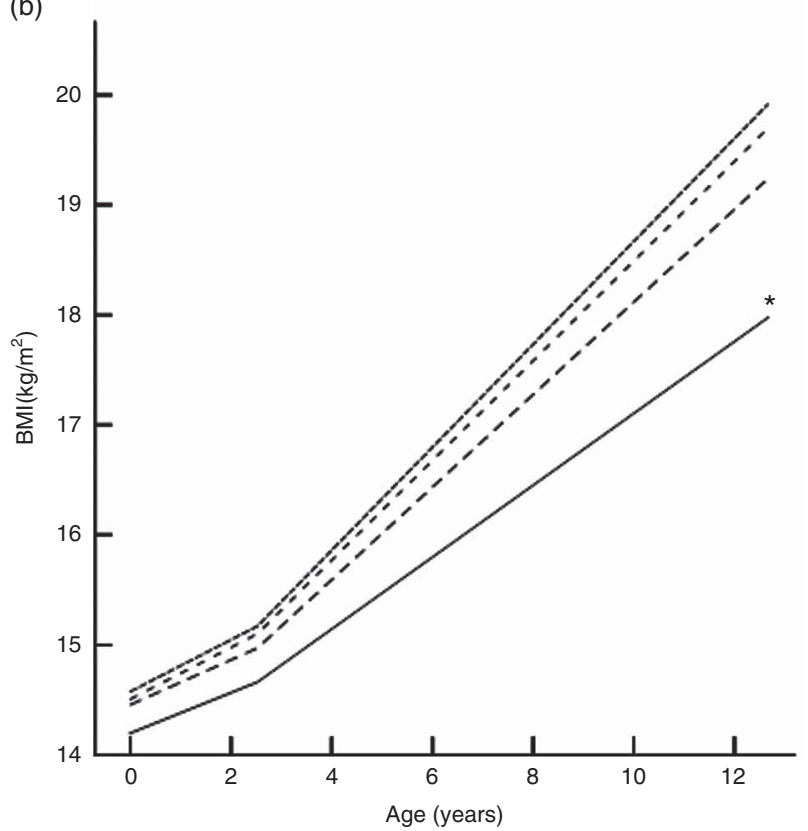

Fig. 4 Mean BMI (adjusted for birth weight) by age, according to social mobility between childhood and adolescence (- - - - high-high/medium (males $n$ 137, females $n$ 126); - - - medium-high (males $n 454$, females $n 426$ ); - - - mediummedium (males $n$ 220, females $n$ 220); _ , low-medium/ high (males $n$ 59, females $n$ 74)) and sex: (a) males; (b) females. ${ }^{*} P<0.05$ for the difference between classifications of BMI according to social mobility. Populationbased cohort of children born between 1994 and 1999, first evaluated between 1999 and 2000, and followed up between 2009 and 2011, Cuiabá, Brazil

Thus, in Brazil, increasing social mobility of the lower economic classes may have decreased the risk of increasing adiposity by reducing stunting. In scenarios without stunting, increasing adiposity is a risk and this may explain observed differences in the association between social mobility, adiposity and health-related behaviours in developed nations. For instance, with greater upward mobility, Finnish adolescents were more likely to improve their health-related behaviours (e.g. decreases in smoking, use of drugs and alcohol, intake of high-sugar foods and coffee, etc, and increases in physical activity, milk consumption, etc.). Moreover, the opposite effect was shown when downward mobility occurred, relative to those who remained in the same economic class $^{(30)}$.

Previous analyses in this Brazilian population have shown that the association between lifestyle factors (e.g. smoking, experimentation with alcohol, overall diet) and social mobility does not remain statistically significant when adjusted for SEP at childhood ${ }^{(31)}$, indicating that these lifestyle factors were more strongly associated with initial SEP than social mobility.

Another explanation for the lack of association between rate of BMI change and social mobility is the short evaluation period (11 years). This period may be too short to observe the impact of social mobility on adiposity. Furthermore, we were unable to pinpoint the precise time of each family's change from one SEP to another; if the change had occurred shortly (i.e. a few years) before the second evaluation, its impact may not yet have occurred.

The strengths of the present study are the measurement of family SEP prospectively at pre-school age and adolescence. There is some indication that the association between childhood SEP and adulthood obesity may be stronger when childhood SEP is measured in childhood rather than retrospectively recalled during adulthood ${ }^{(32)}$. In addition, inclusion of birth weight in the analysis strengthens the conclusion that SEP influences adiposity independently of biological factors.

Although there was loss of subjects to follow-up, the numbers of subjects lost in each SEP, as well as other characteristics of the study population, were not significantly different ${ }^{(33)}$. The criteria used to measure SEP and social mobility in the present study were not originally developed to assess health-related outcomes, but these criteria take into account the educational level of the head of the family and they have been successfully used in other epidemiological studies ${ }^{(34)}$. In addition, the association between adiposity and maternal schooling observed in the current study was similar to that observed when economic criteria are used.

Rapid weight gain in early life, particularly after infancy, is related to increased risk of adult disease ${ }^{(35)}$. In the current study, a high BMI during childhood was also observed during adolescence for subjects from families in a high SEP at childhood, with no effect of social mobility. 
Table 2 Results from linear mixed-effects models for association of BMI ( $\mathrm{kg} / \mathrm{m}^{2}$; log-transformed values) with SEP in childhood and social mobility between childhood and adolescence. Population-based cohort of children born between 1994 and 1999, first evaluated between 1999 and 2000, and followed up between 2009 and 2011, Cuiabá, Brazil

\begin{tabular}{|c|c|c|c|c|c|c|}
\hline & \multicolumn{3}{|c|}{ Males } & \multicolumn{3}{|c|}{ Females } \\
\hline & $B$ & SE & $P$ value & $B$ & $\mathrm{SE}$ & $P$ value \\
\hline \multicolumn{7}{|l|}{$\begin{array}{l}\text { Model: SEP at childhood } \\
\text { BMl at birth (intercept) }\end{array}$} \\
\hline High & -0.001 & 0.016 & 0.92 & 0.023 & 0.014 & $0 \cdot 10$ \\
\hline Medium & -0.006 & 0.014 & 0.67 & 0.021 & 0.011 & 0.07 \\
\hline Low & - & - & - & - & - & - \\
\hline \multicolumn{7}{|l|}{ Rate of change of BMI } \\
\hline Age $\times$ high SEP & 0.006 & 0.002 & 0.02 & 0.006 & 0.002 & $<0.01$ \\
\hline Age $\times$ medium SEP & 0.002 & 0.002 & 0.32 & 0.004 & 0.001 & 0.01 \\
\hline Age $\times$ low SEP & - & - & - & - & - & - \\
\hline Birth weight $(\mathrm{kg})$ & 0.085 & 0.006 & $<0.01$ & 0.108 & 0.006 & $<0.01$ \\
\hline \multicolumn{7}{|l|}{ Model: social mobility } \\
\hline \multicolumn{7}{|l|}{ BMI at birth (intercept) } \\
\hline High-high/medium & -0.001 & 0.016 & 0.93 & 0.023 & 0.014 & $0 \cdot 10$ \\
\hline Medium-medium & -0.006 & 0.014 & 0.68 & 0.023 & 0.012 & 0.06 \\
\hline Medium-high & -0.006 & 0.015 & 0.69 & 0.018 & 0.013 & 0.17 \\
\hline Low-medium/high & - & - & - & - & - & - \\
\hline \multicolumn{7}{|l|}{ Rate of change of BMI } \\
\hline Age $\times$ high-high/medium & 0.006 & 0.002 & 0.02 & 0.006 & 0.002 & $<0.01$ \\
\hline Age × medium-medium & 0.002 & 0.002 & 0.42 & 0.004 & 0.002 & 0.03 \\
\hline Age $\times$ medium-high & 0.003 & 0.002 & 0.21 & 0.005 & 0.002 & $<0.01$ \\
\hline Age $\times$ low-medium/high & - & - & - & - & - & - \\
\hline Birth weight $(\mathrm{kg})$ & 0.085 & 0.005 & $<0.01$ & 0.108 & 0.006 & $<0.01$ \\
\hline
\end{tabular}

SEP, socio-economic position.

\section{Acknowledgements}

Acknowledgements: The authors are extremely grateful to the coordinator of the school census and all the mothers, children/adolescents and staff who made this study possible. Financial support: This work was supported by the Brazilian National Research Council (CNPq), the Research Council of State of Mato Grosso (FAPEMAT) and by a scholarship from the Brazilian Research and Graduate Teaching Support Coordination (CAPES). CNPq, FAPEMAT and CAPES had no role in the design, analysis or writing of this article. Conflict of interest: The authors declare that they have no competing interests. Authorship: A.P.M., R.S. and R.M.V.G.-S. were responsible for the data analysis (including the specific longitudinal analysis), data interpretation and literature search. A.P.M., M.G.F. and R.M.V.G.-S. designed and conducted the analysis of the School Census data, and data collection at baseline and follow-up. All the authors participated in the study's conception and design, and in writing the manuscript. Ethics of human subject participation: The study was approved by the Ethics Committee of the Júlio Müller University Hospital, Federal University of Mato Grosso (651/ CEP-HUJM/2009 Protocol). Parents or guardians of the participating adolescents gave written consent.

\section{Supplementary material}

To view supplementary material for this article, please visit http://dx.doi.org/10.1017/S1368980015001809

\section{References}

1. Malik VS, Willett WC \& Hu FB (2013) Global obesity: trends, risk factors and policy implications. Nat Rev Endocrinol 9, $13-27$.

2. Monteiro CA, Conde WL \& Popkin BM (2007) Incomespecific trends in obesity in Brazil: 1975-2003. Am J Public Health 97, 1808-1812.

3. Schmidt MI, Duncan BB, Azevedo e Silva G et al. (2011) Chronic non-communicable diseases in Brazil: burden and current challenges. Lancet 377, 1949-1961.

4. Ball K \& Mishra GD (2006) Whose socioeconomic status influences a woman's obesity risk: her mother's, her father's, or her own? Int J Epidemiol 35, 131-138.

5. Langenberg C, Hardy R, Kuh D et al. (2003) Central and total obesity in middle aged men and women in relation to lifetime socioeconomic status: evidence from a national birth cohort. J Epidemiol Community Health 57, 816-822.

6. Kendzor DE, Caughy MO \& Owen MT (2012) Family income trajectory during childhood is associated with adiposity in adolescence: a latent class growth analysis. BMC Public Health 12, 611.

7. Heraclides A \& Brunner E (2010) Social mobility and social accumulation across the life course in relation to adult overweight and obesity: the Whitehall II study. J Epidemiol Community Health 64, 714-719.

8. Krzyzanowska M \& Mascie-Taylor CG (2011) Intra- and intergenerational social mobility in relation to height, weight and body mass index in a British national cohort. J Biosoc Sci 43, 611-618.

9. Monteiro CA, Benicio MHD, Conde WL et al. (2010) Narrowing socioeconomic inequality in child stunting: the Brazilian experience, 1974-2007. Bull World Health Organ 88, 305-311.

10. Aitsi-Selmi A, Batty GD, Barbieri MA et al. (2013) Childhood socioeconomic position, adult socioeconomic position and social mobility in relation to markers of adiposity in early 
adulthood: evidence of differential effects by gender in the 1978/79 Ribeirao Preto cohort study. Int J Obes (Lond) 37, 439-447.

11. Barros AJ, Victora CG, Horta BL et al. (2006) Effects of socioeconomic change from birth to early adulthood on height and overweight. Int $J$ Epidemiol 35, 1233-1238.

12. de Bem Lignani J, Sichieri R, Burlandy L et al. (2011) Changes in food consumption among the Programa Bolsa Família participant families in Brazil. Public Health Nutr 14, 785-792.

13. Instituto Brasileiro de Geografia e Estatística (2001) Demographic Census 2000: Population and Household Characteristics - Universe Results. http://www.ibge.gov.br/ english/estatistica/populacao/censo2000/2001 (accessed December 2013).

14. Gonçalves-Silva RMV, Valente JG, Lemos-Santos MGF et al. (2005) Tabagismo no domićlio e baixa estatura em menores de cinco anos. Cad Saude Publica 21, 1540-1549.

15. Programa das Nações Unidas para o Desenvolvimento (2003) Human Development Atlas in Brazil. http://www.pnud.org.br/ IDH/Default.aspx?indiceAccordion=1\&li=li_AtlasMunicipios (accessed December 2013).

16. Tome FS, Cardoso VC, Barbieri MA et al. (2007) Are birth weight and maternal smoking during pregnancy associated with malnutrition and excess weight among school age children? Braz J Med Biol Res 40, 1221-1230.

17. Goncalves-Silva RM, Sichieri R, Ferreira MG et al. (2012) The school census as a search strategy for children and adolescents in epidemiological studies. Cad Saude Publica 28, 400-404.

18. Lohman TG, Roche AF \& Martorell R (1988) Anthropometric Standardization Reference Manual. Champaign, IL: Human Kinetics Books.

19. World Health Organization (2006) WHO Child Growth Standards: Length/Height-for-Age, Weight-for-Age, Weightfor-Length, Weight-for-Height and Body Mass Index-forAge: Methods and Development. Geneva: WHO Multicentre Growth Reference Study Group.

20. World Health Organization (2007) Growth Reference Data for 5-19 Years: Body Mass Index-for-Age, Length/Heightfor-Age and Weight-for-Height. Geneva: WHO.

21. World Health Organization (1995) Physical Status: The Use and Interpretation of Anthropometry Report of a WHO Expert Committee, WHO Technical Report Series no. 854. Geneva: WHO.

22. Associação Brasileira de Emprasas de Pesquisa (2002) Critério de Classificação Econômica. São Paulo: ABEP; available at http://www.abep.org/novo/Content.aspx? ContentID $=302$

23. Associação Brasileira de Emprasas de Pesquisa (2008) Critério de Classificação Econômica Brasil. São Paulo: ABEP; available at http://www.abep.org/novo/Content. aspx?ContentID $=302$

24. Berkey CS \& Colditz GA (2007) Adiposity in adolescents: change in actual BMI works better than change in BMI $\mathrm{z}$ score for longitudinal studies. Ann Epidemiol 17, 44-50.

25. Cole TJ, Faith MS, Pietrobelli A et al. (2005) What is the best measure of adiposity change in growing children: BMI, BMI \%, BMI z-score or BMI centile? Eur J Clin Nutr 59 , 419-425.

26. Fitzmaurice GM, Laird NM \& James HW (2011) Linear Mixed Effects Model. Applied Longitudinal Analysis, 2nd ed., pp. 189-240. Boston, MA: John Wiley \& Sons.

27. Lourenco BH, Villamor E, Augusto RA et al. (2012) Influence of early life factors on body mass index trajectory during childhood: a population-based longitudinal analysis in the Western Brazilian Amazon. Matern Child Nutr 11, 240-252.

28. Matijasevich A, Santos IS, Menezes AM et al. (2012) Trends in socioeconomic inequalities in anthropometric status in a population undergoing the nutritional transition: data from 1982, 1993 and 2004 Pelotas birth cohort studies. BMC Public Health 12, 511.

29. Paes-Sousa R, Santos LM \& Miazaki ES (2011) Effects of a conditional cash transfer programme on child nutrition in Brazil. Bull World Health Organ 89, 496-503.

30. Karvonen S, Rimpela AH \& Rimpela MK (1999) Social mobility and health related behaviours in young people. J Epidemiology Community Health 53, 211-217.

31. Hackenhaar ML, Sichieri R, Muraro AP et al. (2013) Social mobility, lifestyle and body mass index in adolescents. Rev Saude Publica 47, 942-951.

32. Senese LC, Almeida ND, Fath AK et al. (2009) Associations between childhood socioeconomic position and adulthood obesity. Epidemiol Rev 31, 21-51.

33. Muraro AP, Gonçalves-Silva RM, Moreira NF et al. (2014) Effect of tobacco smoke exposure during pregnancy and preschool age on growth from birth to adolescence: a cohort study. BMC Pediatr 14, 99.

34. Antunes JLF (2008) Condições socioeconômicas em saúde: discussão de dois paradigmas. Rev Saude Publica 42, 562-567.

35. Victora CG, Adair L, Fall C et al. (2008) Maternal and child undernutrition: consequences for adult health and human capital. Lancet 371, 340-357. 